\title{
Studies on phytosterol acetate esters and phytosterols liposomes
}

\author{
Lifen $\mathrm{HOU}^{1}$ (D), Xiangyang $\mathrm{SUN}^{2}$, Li PAN ${ }^{3}$, Hongyan WANG ${ }^{1}$, Keren GU ${ }^{1 *}$
}

\begin{abstract}
Phytosterols (PS) and phytosterol esters have been widely used in the food and health product industries as cholesterol-lowering agents. In order to improve theirs dispersity and bioavailability in low lipid media, PS and phytosterol acetate ester (PAE) were embedded into liposomes in the study. The effects of different PAE or PS concentrations on liposome properties were determined and interactions between PAE or PS and phospholipids were also explored. PAE and PS can be well embedded in liposomes, and the encapsulation rate was more than $90 \%$. Compared to SPC liposomes, no significant difference $(P>0.05)$ in particle size $(60 \mathrm{~nm})$ and zeta potential $(-15 \mathrm{mV})$ were observed between liposomes with PAE or PS. Liposomes were spherical, with smooth surfaces and uniform size distributions. The results of X-ray powder diffractometry (XRD) revealed that PAE and PS were amorphously embedded in liposomes. The results from the Fourier-transform infrared (FTIR) and Differential scanning calorimeter (DSC) analysis indicated that PAE or PS changed the structure of the lipid membrane by interacting with phospholipids in the liposomes. Low doses of PAE had a stabilizing effect on the liposome membrane structure.
\end{abstract}

Keywords: phytosterol acetate esters; phytosterols; liposome; effect; properties.

Practical Application: The preparation of ideal and stable nanoparticles is beneficial to improve the bioavailability of phytosterol esters or phytosterols and broaden its application field.

\section{Introduction}

PS can effectively reduce the total cholesterol and low density lipoprotein in serum by inhibiting cholesterol absorption in the intestinal tract (Cedó et al., 2019). PS also have antitumor effects (Blanco-Vaca et al., 2019) and immunity and antiinflammatory activities (Hu et al., 2017). PS are insoluble in water and have poor solubility in lipids, which limits their application. In recent years, phytosterol esters have been widely used in the food and health product industries as cholesterollowering agents (Lin et al., 2018; Scholz et al., 2016; Rui et al., 2017; Gachumi et al., 2021; Pega et al., 2017) since they are fatsoluble. However, phytosterol esters as food additives require a high-fat environment. Thus, consumers may have to eat more fat to benefit from the effect of phytosterol esters on lowering serum cholesterol. Dispersion or emulsification of phytosterol esters and PS may be an interesting solution to this issue, but there have been few reports on this approach (Luo et al., 2016; Wang et al., 2017; Panpipat et al., 2013).

Liposomes can encapsulate hydrophilic, hydrophobic, and amphoteric substances, and thus the application of phytosterol esters and PS incorporated into liposomes can be expanded to non-fat or low-fat foods. The amount of sterol esters in small unilamellar vesicles has been shown to be higher than that in multilamellar vesicles (Salmon \& Hamilton, 1995). Furthermore, the bioavailability of the active ingredient is influenced by the size of the particle dispersion; the smaller the particle size and higher the surface/volume ratio are, the higher the bioavailability (Chen \& Fu, 2019). Based on this, an appropriate method can be chosen to prepare liposomes. Phytosterol esters and PS can be mixed into and interact with the bilayer of the lipid membrane, which resulted in changes in the membrane structure and performance. Several studies have shown that PS could significantly improve the stability of liposomes compared with cholesterol (Jovanović et al., 2018; Tai et al., 2019) . Another study showed that PS anchored to the membrane and exhibited better performance for membrane protection than gallic acid (Liu et al., 2016). Previously, blends of phytosterol esters $(>90 \%, \mathrm{w} / \mathrm{w})$ were used to prepare soybean phospholipid liposomes toward improving the encapsulation rate of ascorbic acid (Alexander et al., 2012). Furthermore, studies have found that cholesterol acetate ester at a low concentration of $0.1 \mathrm{~mol} \%$ has a certain antioxidant effect on lipid membranes (Malcolmson et al., 1997). However, there have been no studies on the incorporation of short-chain phytosterol esters to liposomes. Short chain fatty acids (mainly includes acetic acid, propionic acid and butyric acid), metabolites produced by the fermentation of dietary fiber by intestinal flora, play important role in maintaining intestinal environment and function of epithelial cells ( $\mathrm{Hu} \& \mathrm{Hu}, 2020)$.

In this study, soybean phospholipid liposomes were prepared with PAE or PS by a thin-film ultrasonic method. In addition, we determined the influence of different concentrations of incorporated PAE and PS on the particle size, polydispersity index (PDI), zeta potential, encapsulation efficiency and microstructure of the liposomes, as well as the interactions between PAE or PS and phospholipids in the membranes. The results of this study 
provide a general reference for further exploring the potential application of phytosterols and their esters in foods.

\section{Materials and methods}

\subsection{Materials}

Soybean phospholipids (SPC, 98\% purity) were purchased from Shenyang Tianfeng Biological Pharmaceutical (Liaoning, China). Phytosterols (97\% purity; 56\% $\beta$-sitosterol, 30\% stigmasterol, and $14 \%$ campesterol) were purchased from Shanghai Yihe Biotechnology (Shanghai, China). Phytosterol acetate ester (PAE) was prepared in the laboratory ( $97 \%$ purity). $\beta$-sitosterol standard was purchased from Puruifa Biotechnology Co. Ltd. (Chengdu, Sichuan, China, $99.99 \%$ purity). Squalane was purchased from Shanghai Macklin Biochemical Co. Ltd. (Shanghai, China, 99\% purity). N-hexane was chromatographically pure, and all the reagents used in this study were analytical grade.

\subsection{Liposome preparation}

The liposomes were prepared by following the method described by Mohan et al. (2016) with some modifications. Eighty milligrams of SPC, $40 \mathrm{mg}$ of tween-80, and 2 or $4 \mathrm{mg}$ of PAE or PS were precisely weighed and placed in a round-bottom flask, $10 \mathrm{~mL}$ of organic solvent (chloroform:methanol = 2:1, V: V) was added, and the mixture was kept out of the light at room temperature for 15-30 min. The organic solvent was removed by rotary evaporation (water bath temperature $50^{\circ} \mathrm{C}$ ) to form a uniform film on the wall of the round-bottom flask. Then, the flask was spun for an additional 30 min under a vacuum of $0.1 \mathrm{MPa}$. Ten milliliters of $0.02 \mathrm{~mol} / \mathrm{L}$ phosphate buffer solution (PBS, pH 7.4, $0.15 \mathrm{~mol} / \mathrm{L} \mathrm{NaCl}$ ) was injected to hydrate the lipid membrane for $10 \mathrm{~min}$. Sonication was carried out in an ice bath with an ultrasonic probe ( $200 \mathrm{~W}, 8 \mathrm{~min}$, and 1s on, $1 \mathrm{~s} \mathrm{off})$ (ultrasonic material emulsifier, Shanghai Hannuo Instrument, China). The liposomes without PAE or PS were prepared by the same method. The final concentration of phospholipids was $8 \mathrm{mg} / \mathrm{mL}$.

\subsection{Characterization of liposomes}

Average size, PDI, and zeta potential analysis

Dynamic light scattering (DLS) is a common technique for measuring the diameter of particles exhibiting Brownian motion in a solution. The average particle size, $\mathrm{PDI}$, and zeta potential were measured by DLS (Zetasizer Nano, ZS90, Malvern Instruments, Worcestershire, UK). The sample was diluted 100 times with high-purity water and placed in the spectrometer immediately after dilution. Three parallel samples were measured at $25^{\circ} \mathrm{C}$. The data is expressed as mean \pm standard deviation.

\section{The encapsulation efficiency (EE) of phytosterols}

The lipid content of liposomes was obtained by extracting lipids from liposomes using a chloroform-methanol extraction method as described by Wang et al. (2017). The PAE content was determined after saponification of lipid samples. We added $10 \mathrm{~mL}$ of $\mathrm{KOH}$-ethanol solution $(1.0 \mathrm{~mol} / \mathrm{L})$ to the lipid samples, placed it in a water bath at $80^{\circ} \mathrm{C}$ for reflux and condensation, magnetically stirred for $2 \mathrm{~h}$, and cool it to room temperature. Next, we added saturated sodium chloride solution $(20 \mathrm{~mL})$, injected ethyl ether $(15 \mathrm{~mL})$, and transferred the mixture to the separation funnel and extracted thrice; all three extracts were combined. The ethyl ether extract was washed and neutralized with distilled water, and then a certain amount of anhydrous sodium sulfate was added to the ether extract for dehydration, followed by filtration and evaporation to remove the ether to obtain the saponifiable matter.

The following conditions were applied for Gas chromatography (GC-2010 Plus Gas chromatograph) analysis of PAE using DB$1 \mathrm{HT}$ chromatography column. FID temperature: $300^{\circ} \mathrm{C}$; gas flow rate: hydrogen $30 \mathrm{~mL} / \mathrm{min}$, air $300 \mathrm{~mL} / \mathrm{min}$; carrier gas: nitrogen $25 \mathrm{~mL} / \mathrm{min}$; injection temperature: $30{ }^{\circ} \mathrm{C}$; split sampling, split ratio was 50:1; Column temperature: initially $180^{\circ} \mathrm{C}$ for $1 \mathrm{~min}$, and was increased to $300^{\circ} \mathrm{C}$ at $30^{\circ} \mathrm{C} / \mathrm{min}$ for $10 \mathrm{~min}$; injection volume: $1.0 \mathrm{~L}$; column pressure: $10 \mathrm{psi}$.

Squalane $(100 \mathrm{mg})$ was accurately weighed in a $25 \mathrm{~mL}$ volumetric flask, and hexane was volumetric to scale and used as an internal standard solution. The $\beta$-sitosterol standard was measured and dissolved in $\mathrm{n}$-hexane $(50 \mathrm{~mL})$, which was used as the standard storage liquid. $\beta$-sitosterol solutions $(0,0.5,1.0,2.0$, $4.0,6.0$, and $8.0 \mathrm{~mL}$ ) were prepared and stored in $10 \mathrm{~mL}$ volumetric flasks, respectively. Squalane internal standard solution $(1.0 \mathrm{~mL})$ was added to each bottle, and then the volume was made up to $10 \mathrm{~mL}$. The standard solution ranged in concentration from 0.1 to $1.6 \mathrm{mg} / \mathrm{mL}$. The linear regression equation and correlation coefficient between $\beta$-sitosterol and internal standard were found to be $\mathrm{A}=0.5395 \mathrm{C}+0.0674$ and $\mathrm{R}^{2}=0.9994$ with Squalane as internal standard substance. The encapsulation efficiency of PAE was calculated using $\beta$-sitosterol as the index.

\section{Morphological analysis}

The morphology of the liposomes was determined using transmission electron microscopy (TEM) with a HT7700 microscope (Hitachi, Tokyo, Japan). The liposome suspension was placed on a copper grid for $8 \mathrm{~min}$ and negatively stained by a phosphotungstic acid solution (2\%) for $5 \mathrm{~min}$. Excess solution was removed with filter paper, and the air-dried stained samples were used for imaging. The micrographs were acquired using a voltage of $100 \mathrm{kV}$ and $40 \mathrm{k} \times$ magnification.

\section{$X$-ray diffraction $(X R D)$ analysis}

The crystal state of freeze-dried SPC, PBE liposomes, and free PBE was analyzed by MiniFlex 600 (Rigaku, Tokyo, Japan). Diffraction patterns were recorded over a range of $2 \theta$ angles from $5^{\circ}$ to $60^{\circ}$ at a speed of $0.15 \mathrm{~s} / \mathrm{step}$ and a scan step size of $0.02^{\circ}$ at a rate of $5^{\circ} \cdot \mathrm{min}^{-1}$. Samples were irradiated with $\mathrm{Cu}-\mathrm{Ka}$ radiation at a $30 \mathrm{~mA}$ and $40 \mathrm{kV}$.

\section{Fourier-transform infrared spectroscopy analysis}

FTIR analysis was performed on the powder purified product with a Spectrum TWO UATR (PerkinElmer, USA) in the range of $4000-400 \mathrm{~cm}^{-1}$ using 16 scans at a resolution of $0.5 \mathrm{~cm}^{-1}$. FTIR 
analysis was also performed on the liposome samples. Three parallel samples were tested.

\section{DSC analysis}

Heating phase diagrams of the freeze-dried liposomes were acquired with a differential scanning calorimeter (DSC 8000, PerkinElmer, USA). The experiments were carried out from 50 to $200{ }^{\circ} \mathrm{C}$ at a heating rate of $10{ }^{\circ} \mathrm{C} / \mathrm{min}$ under nitrogen flow at $40 \mathrm{~mL} / \mathrm{min}$. The DSC data was analyzed with the manufacturer software supplied, and the plots were drawn using Pyris version 13.

\section{Data analysis}

Analysis of variance (ANOVA) was performed using the IBM SPSS21.0 Statistics software (IBM Analytics, Armonk, USA), followed by Duncan's test at a significance level of $P<0.05$. Each sample was tested in triplicate.

\section{Results and discussion}

\subsection{Characterization of liposomes}

Particle size, PDI, zeta potential and encapsulation efficiency

The particle size, PDI (A) and encapsulation efficiency (B) of the liposomes are given in Figure 1. No significant differences $(P>0.05)$ were observed in the particle sizes and encapsulation efficiency of the vesicular formulations.

The average particle size of all liposomes was approximately $60 \mathrm{~nm}$. It was found that the incorporation of phytosterol esters did not significantly change (Gorrissen et al., 1980) or decreased the particle size of liposomes (Wang et al., 2017). The incorporated phytosterol esters molecules may replace some phospholipid molecules or form lipid rafts in the membrane, leading to tighter packing of the membrane lipids, which in turn reduces or does not significantly change the average particle diameter of liposomes (Wang et al., 2017). For PS, it was reported by Tai et al. (2018), that the incorporation could increase the particle size of liposome vesicles. In this study, the incorporation concentration of PS was small, which failed to generate the apparent space occupation in the membrane. The small size of the liposomes
$(<100 \mathrm{~nm})$ with PAE and PS incorporated, is beneficial because the increased surface area improves bioavailability.

Zeta potential is an important stability parameter, which can be used to predict the storage stability of liposome vesicles (Karpuz et al., 2021). The zeta potential of all formulations of liposomes was approximately $-15 \mathrm{mV}$. The medium zeta potential plays a positive role in the stability of the system by causing repulsion forces among particles to prevent aggregation. While the addition of Tween 80 , which is often used as a solvent enhancement in the preparation of liposomes, can increase the steric repulsion and increase the ability of particles to resist aggregation or fusion (Piazzini et al., 2018). After being stored for 1 month at $4{ }^{\circ} \mathrm{C}$, the particle size of PAE and PS liposome increased from about $60 \mathrm{~nm}$ to $70 \mathrm{~nm}$, and which of without incorporation of PAE and PS liposome increased from about $60 \mathrm{~nm}$ to $90 \mathrm{~nm}$. These results indicated that low concentrations of PAE and PS could improve the storage stability of liposomes.

The PDI of the liposomes with PAE and PS increased slightly compared to without the addition of liposomes, but there was no significant difference in the concentration. The PDI of all liposomes was less than 0.3 , indicating a narrow size distribution within the formulations (Chen et al., 2019; Cui et al., 2018).

The encapsulation efficiency of PAE and PS in the liposome was found to be $>90 \%$ (Figure 1B), indicating that within this range (1/40-1/20), PAE and PS could be effectively embedded in the lipid bilayer. As the ability to successfully construct ideal phytosterol esters liposomes increases, the potential of food applications increases.

\section{Morphological analysis}

To confirm the formation of vesicles of liposome, transmission electron microscopy was also carried out. The whitish spherical liposome particles with smooth surfaces and uniform particle size distributions are shown in Figure 2. The particle size of liposomes is consistent with the DLS results. Additionally, the addition of PAE or PS at different concentrations did not significantly change the liposome microstructure.
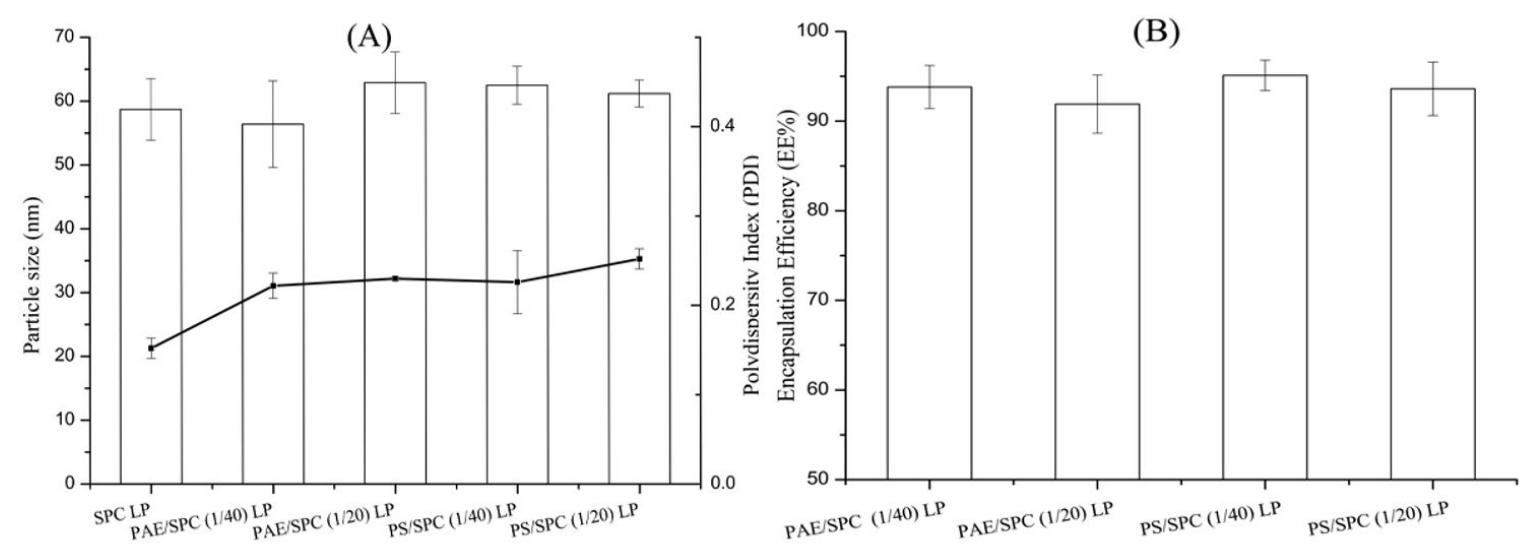

Figure 1. Size distribution, polydispersity index (PDI) and encapsulation efficiency of liposomes. 


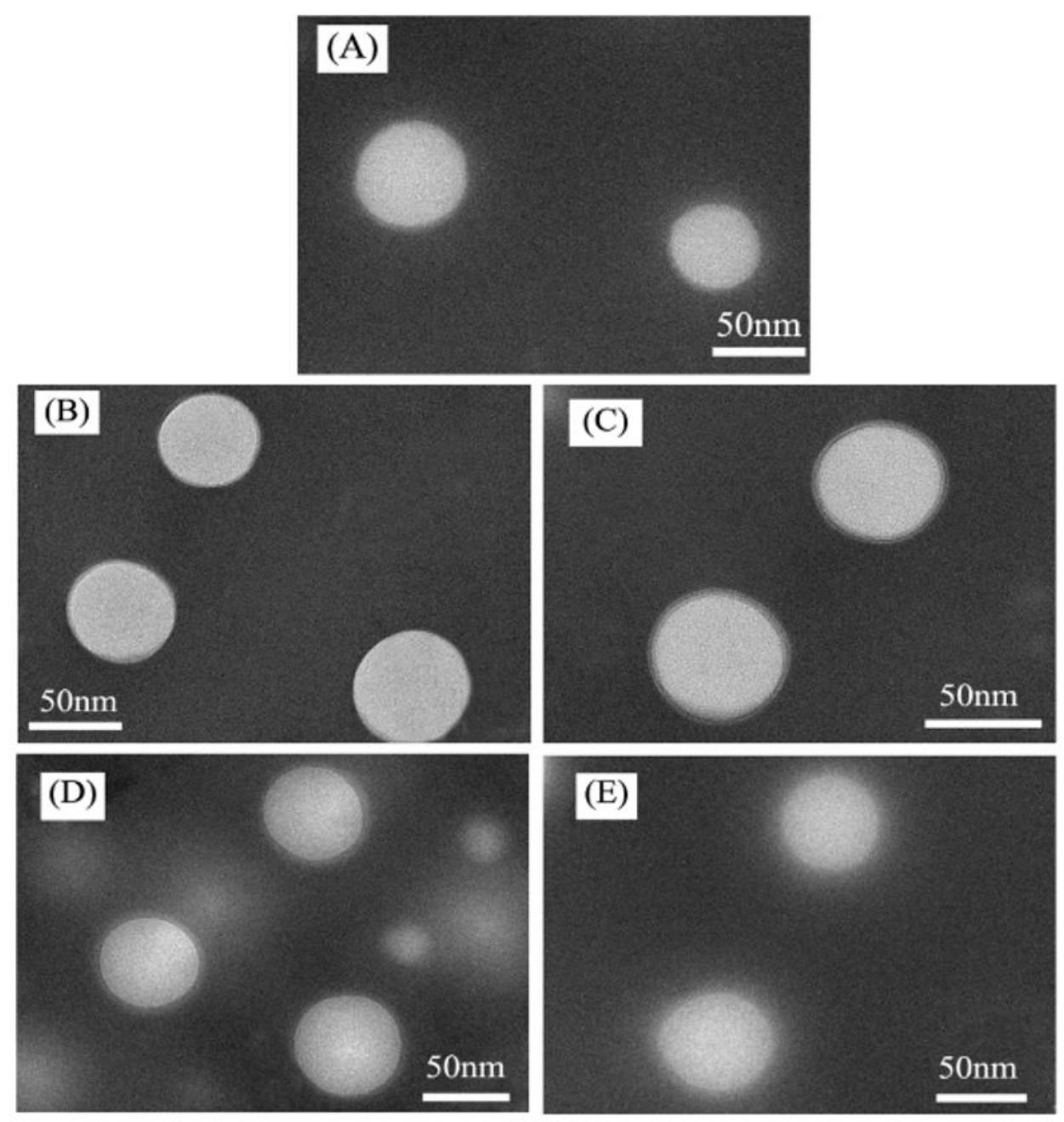

Figure 2. TEM images of SPC (A), PAE/SPC (1/40) (B), PAE/SPC (1/20) (C), PS/SPC (1/40) (D), and PS/SPC (1/20) (E) liposomes.

\section{$X R D$ analysis}

The X-ray diffraction pattern for free PS, PAE, PS/SPC (1/20), PAE/SPC (1/20), and SPC liposomes are shown in Figure 3. It was clear that free PS and PAE were both present in a crystalline state with sharp peaks in the XRD pattern. The main characteristic peaks of PS or PAE were absent in the XRD pattern of liposomes, suggesting that PS and PAE were molecularly dispersed or soluble state in the liposomes lipid bilayers. This is consistent with the literature (Huang et al., 2020). The loss of crystallinity of the embedded material due to liposome encapsulation has been shown to be evidence of the interaction between the embedded material and the phospholipid molecules in the liposome (Nkanga \& Krause, 2018; Okafor et al., 2019). This indicated that PAE and PS were embedded in liposomes respectively.

\section{FTIR analysis}

FTIR spectroscopy was used to monitor the interactions between the exogenous substances and lipid acyl chains or head groups of the phospholipids, which could reflect structural and conformational changes in the liposomes (Savaghebi et al., 2019; Pinilla et al., 2019). FTIR analysis was carried out (Figure 4), and features such as $\mathrm{CH}_{2}$ antisymmetric stretching and symmetric

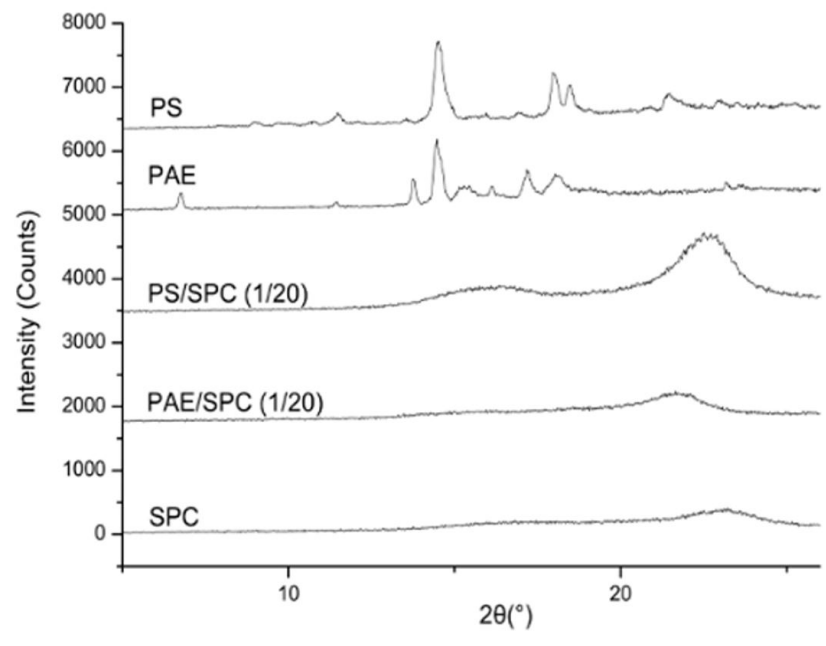

Figure 3. The X-ray diffraction pattern for free PS and PAE, PS/SPC, PAE/SPC, and SPC liposomes.

stretching at $\sim 2924$ and $\sim 2850 \mathrm{~cm}^{-1}$, respectively, C=O stretching at $\sim 1735 \mathrm{~cm}^{-1}$, and $\mathrm{PO}_{2}^{-}$antisymmetric double stretching bands at $\sim 1240 \mathrm{~cm}^{-1}$ were analyzed. Owing to similar main peaks in the FTIR spectra of different liposomes, this indicates that the 
incorporated PAE and PS did not cause a significant chemical reaction in the membrane. These findings were in agreement with previous studies (Tai et al., 2018).

The detailed wavenumbers of the relevant characteristic peaks are shown in Figure 4. For the acyl chain, the peak position of this band indicates the level of order or disorder of the membrane (Jia-Yu et al., 2019; Altunayar Unsalan et al., 2018), where a lower wavenumber represents a more ordered state and vice versa. This also means that the gauche- and trans-conformations in the system are interconvertible. PAE induced a slight shift toward lower wavenumbers for the $\mathrm{CH}_{2}$ antisymmetric stretching bands in the lipid membranes. This suggests that the addition of PAE increased the lipid hydrocarbon chain conformational order. These results are consistent with previous studies on liposomes containing different hydrophobic compounds (Paliwal et al., 2019; Marín et al., 2018). This is consistent with the previous particle size analysis results. While there were indistinctive changes in the $\mathrm{CH}_{2}$ antisymmetric stretching bands in PS liposomes, this is similar to the results presented by Tai et al.(2018).

The hydration state of the interfacial and head groups of the SPC liposomes was monitored by the $\mathrm{C}=\mathrm{O}$ stretching, and $\mathrm{PO}_{2}{ }^{-}$antisymmetric double stretching. The $\mathrm{C}=\mathrm{O}$ stretching band shifted slightly to a lower wavenumber with the different concentrations of PAE and PS in the liposomes. This result indicates that hydrogen bonding around the $\mathrm{C}=\mathrm{O}$ groups of the liposomes was strengthened. The literature showed that the wavenumber of $\mathrm{C}=\mathrm{O}$ in $\beta$-sitosterol incorporated liposomes was shifted lower $\left(1736.20 \mathrm{~cm}^{-1}\right.$ to $\left.1735.19 \mathrm{~cm}^{-1}\right)$ (Tai et al., 2018). Studies also have shown that the cholesterol ester is located in the carbonyl groups of the lipid membrane interface (Salmon \& Hamilton, 1995). Asymmetric stretching of the phosphate group can also be a useful indicator when it comes to determining changes in the conformation of the head group (Schmid et al., 2018). The addition of both concentrations PAE and PS reduced the wavenumber of the $\mathrm{PO}_{2}^{-}$antisymmetric band in the lipid membranes, showing that the degree of hydrogen bonding to the $\mathrm{PO}_{2}$-group increased, especially at low concentrations. This result suggests that PAE or PS may compete with polar groups to form hydrogen bonds with surrounding water molecules as the concentration increases. Therefore, these results demonstrate that PAE could induce a stronger intermolecular interaction than PS in liposomes.

The incorporation of PAE induced compositional and structural changes due to the increased hydration of these polar groups and the increased order of alkyl chain.

\section{DSC analysis}

The DSC thermograms of the lyophilized liposomes with different formulations, the transition temperatures and enthalpy changes are shown in Figure 5. The thermograms of lyophilized liposomes with and without incorporating PAE or PS showed non-sharp phase transition peaks. Since natural phospholipids contain mixed fatty acids, their peaks are not sharp (Monpara et al., 2018). Liposomes without the incorporation of PAE or PS had an endothermic peak at $128.05^{\circ} \mathrm{C}$, which was probably related to the phase transition from a gel to liquid crystalline state.
The literature showed that the phase transition temperature $(\mathrm{Tm})$ of dehydrated void soybean phospholipid liposome is $116.8^{\circ} \mathrm{C}$ (Niaz et al., 2018). The difference in Tm could be related to the purity of the soybean phospholipid. Compared with the SPC liposomes, the PAE (Figure 5b, c) and PS (Figure 5d, e) liposomes showed obvious changes in peak position and enthalpy. The peak position of the PAE/SPC (1/40) liposome increased notably to $140.98^{\circ} \mathrm{C}$, while that of the PAE/SPC $(1 / 20)$ liposome was $128.26^{\circ} \mathrm{C}$. The increase in $\mathrm{Tm}$ indicated an increased arrangement of the acyl chains and the thermal stability of the lipid membrane. With the increase of PAE concentration, the increase amplitude of Tm decreased, which may be related to the competition between PAE and phospholipid head group to form hydrogen bonds of water molecules, thus affecting the structure of alkyl chain. The PS contents of $1 / 40$ and $1 / 20$ induced a decrease in the peak position by approximately 15 and $10^{\circ} \mathrm{C}$, respectively, showing that low concentrations of PS have more significant effects, and the reduction of PS increased disorder of the acyl chains and thermal instability of the membrane. Farkas et al. (2004) previously confirmed that the addition of $\beta$-sitosterol

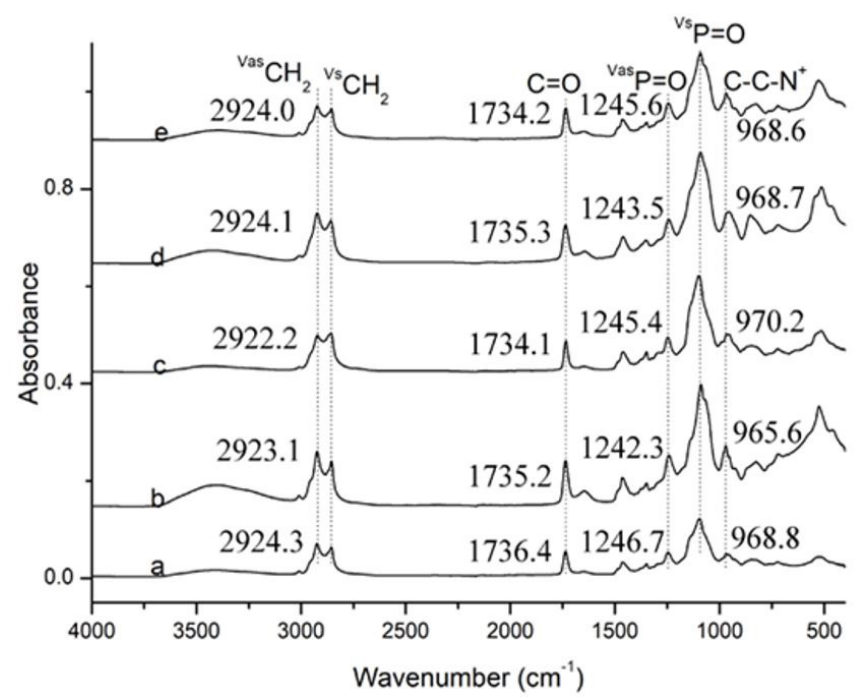

Figure 4. Overall FTIR spectra of SPC (a), PAE/SPC (1/40) (b), PAE/ SPC (1/20) (c), PS/SPC (1/40) (d), and PS/SPC (1/20) (e) liposomes.

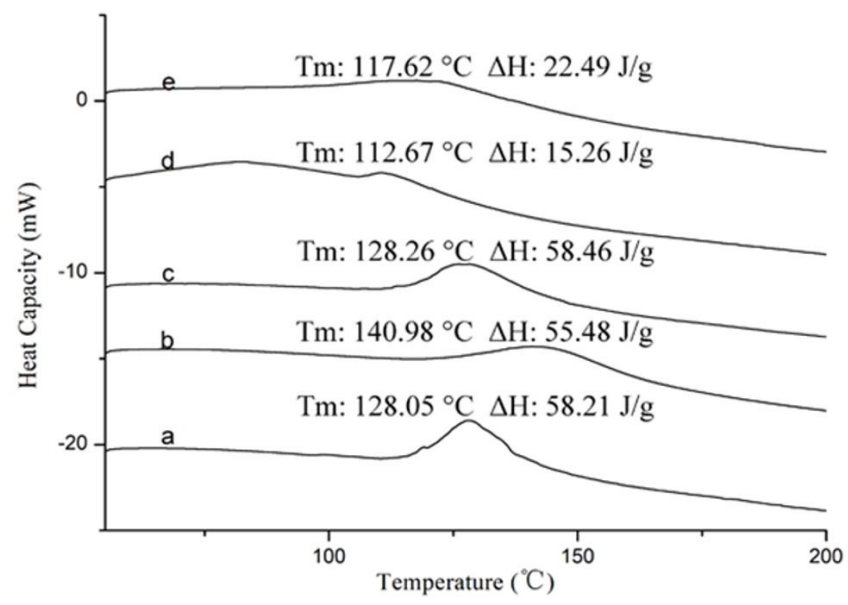

Figure 5. DSC thermograms of SPC (a), PAE/SPC (1/40) (b), PAE/ SPC (1/20) (c), PS/SPC (1/40) (d), and PS/SPC (1/20) (e) liposomes. 
reduces the interaction forces in the lipid bilayer and thereby acts as a liquefier below the phase transition temperature.

Furthermore, the enthalpy variation $(\Delta H)$ reflects the van der Waals interactions between the lipid acyl chains and foreign substances and is related to lipid order. The $\Delta H$ of the SPC, PAE/ SPC $(1 / 40)$ and $(1 / 20)$, and PS/SPC $(1 / 40)$ and $(1 / 20)$ lyophilized liposomes were $58.21,55.48,58.46,15.26$, and $22.49 \mathrm{~J} / \mathrm{g}$, respectively, indicating that PAE has little effect on $\triangle H$, whereas PS reduces it. The thermal phase effects of PAE on lipid membranes have not yet been reported. It has been stated that the enthalpy of DMPC liposomes with $0.2 \mathrm{~mol} \%$ and $0.5 \mathrm{~mol} \%$ of cholesterol stearate is higher than that of cholesterol (Wei et al., 2017), and another study showed that different concentrations of cholesterol could reduce the enthalpy of Dipalmitoylphosphatidylcholine (DPPC) liposomes (Lee \& Chang, 2018). Therefore, the incorporation of PAE/SPC (1/40) and PAE/SPC (1/20) increased the ordering of acyl chains in the liposome bilayer below $\mathrm{Tm}$. These results are consistent with the FTIR analysis.

\section{Conclusions}

PAE and PS at low concentration can be well embedded in liposomes, and the encapsulation efficiecy is above 90\%. PAE and PS liposomes have small particle size, uniform distribution and good stability. Through the study on the molecular interaction between PAE or PS and phospholipid, the properties of PAE and PS liposomes can be further understood. Studies on PAE and PS liposomes have shown that liposomes are a suitable carrier that may be beneficial and provide references for the development and application of functional foods in the future.

\section{Acknowledgements}

The authors acknowledge National Natural Science Foundation of China and the Key Scientific Research Projects of Higher Education Institutions of Henan Province in China for the financial support.

\section{References}

Alexander, M., Acero Lopez, A., Fang, Y., \& Corredig, M. (2012). Incorporation of phytosterols in soy phospholipids nanoliposomes: encapsulation efficiency and stability. Lebensmittel-Wissenschaft + Technologie, 47(2), 427-436. http://dx.doi.org/10.1016/j.lwt.2012.01.041.

Altunayar Unsalan, C., Sahin, I., \& Kazanci, N. (2018). A concentration dependent spectroscopic study of binary mixtures of plant sterol stigmasterol and zwitterionic dimyristoyl phosphatidylcholine multilamellar vesicles: an FTIR study. Journal of Molecular Structure, 1174, 127-132. http://dx.doi.org/10.1016/j.molstruc.2018.02.100.

Blanco-Vaca, F., Cedo, L., \& Julve, J. (2019). Phytosterols in cancer: from molecular mechanisms to preventive and therapeutic potentials. Current Medicinal Chemistry, 26(37), 6735-6749. http://dx.doi.org /10.2174/0929867325666180607093111. PMid:29874991.

Cedó, L., Farràs, M., Lee-Rueckert, M., \& Escolà-Gil, J. C. (2019). Molecular insights into the mechanisms underlying the cholesterollowering effects of phytosterols. Current Medicinal Chemistry, 26(37), 6704-6723. http://dx.doi.org/10.2174/092986732666619082215470 1. PMid:31438826.
Chen, C., \& Fu, X. (2019). Spheroidization on Fructus Mori polysaccharides to enhance bioavailability and bioactivity by anti-solvent precipitation method. Food Chemistry, 300, 125245. http://dx.doi.org/10.1016/j. foodchem.2019.125245. PMid:31352287.

Chen, W., Zou, M., Ma, X., Lv, R., Ding, T., \& Liu, D. (2019). Coencapsulation of EGCG and Quercetin in liposomes for optimum antioxidant activity. Journal of Food Science, 84(1), 111-120. PMid:30548488.

Cui, H., Bai, M., Li, C., Liu, R., \& Lin, L. (2018). Fabrication of chitosan nanofibers containing tea tree oil liposomes against Salmonella spp. in chicken. Lebensmittel-Wissenschaft + Technologie, 96, 671-678. http://dx.doi.org/10.1016/j.lwt.2018.06.026.

Farkas, E., Schubert, R., \& Zelkó, R. (2004). Effect of $\beta$-sitosterol on the characteristics of vesicular gels containing chlorhexidine. International Journal of Pharmaceutics, 278(1), 63-70. http://dx.doi. org/10.1016/j.ijpharm.2004.02.022. PMid:15158949.

Gachumi, G., Poudel, A., Wasan, K. M., \& El-Aneed, A. (2021). Analytical strategies to analyze the oxidation products of phytosterols, and formulation-based approaches to reduce their generation. Pharmaceutics, 13(2), 268. http://dx.doi.org/10.3390/ pharmaceutics13020268. PMid:33669349.

Gorrissen, H., Mackay, A. L., Wassall, S. R., Valic, M. I., Tulloch, A. P., \& Cushley, R. J. (1980). Deuterium magnetic resonance of selectively deuterated cholesteryl esters in dipalmitoyl phosphatidylcholine dispersions. Biochimica et Biophysica Acta, 644(2), 266-272. http:// dx.doi.org/10.1016/0005-2736(81)90384-9. PMid:6894863.

$\mathrm{Hu}, \mathrm{M}$. and $\mathrm{Hu}$, J. (2020). Correlation between short chain fatty acids and metabolic diseases: research progress. Journal International of Pharmaceutics Research, 47(11), 881-886. http://dx.doi.org/10.13220/j. cnki.jipr.2020.11.001.

Hu, Q., Zhuo, Z., Fang, S., Zhang, Y., \& Feng, J. (2017). Phytosterols improve immunity and exert anti-inflammatory activity in weaned piglets. Journal of the Science of Food and Agriculture, 97(12), 41034109. http://dx.doi.org/10.1002/jsfa.8277. PMid:28218810.

Huang, J., Wang, Q., Chu, L. L., \& Xia, Q. (2020). Liposome-chitosan hydrogel bead delivery system for the encapsulation of linseed oil and quercetin: preparation and in vitro characterization studies ScienceDirect. Lebensmittel-Wissenschaft + Technologie, 117, 108615. http://dx.doi.org/10.1016/j.lwt.2019.108615.

Jia-Yu, G. U., Dan-Dan, Y. U., \& Rui-Guang, W. U. (2019). The interaction of evodiamine with liposome mimetic biomembrane: FTIR and DSC study. Guangpuxue Yu Guangpu Fenxi, 39, 1757-1762.

Jovanović, A. A., Balanč, B. D., Ota, A., Ahlin Grabnar, P., Djordjević, V. B., Šavikin, K. P., Bugarski, B. M., Nedović, V. A., \& Poklar Ulrih, N. (2018). Comparative effects of cholesterol and $\beta$-Sitosterol on the liposome membrane characteristics. European Journal of Lipid Science and Technology, 120(9), 1800039. http://dx.doi.org/10.1002/ ejlt.201800039.

Karpuz, M., Atlihan-Gundogdu, E., Demir, E. S., \& Senyigit, Z. (2021). Radiolabeled tedizolid phosphate liposomes for topical application: design, characterization, and evaluation of cellular binding capacity. AAPS PharmSciTech, 22(2), 62. http://dx.doi.org/10.1208/s12249020-01917-4. PMid:33528714.

Lee, H., \& Chang, J. H. (2018). Spherical silica hybrid liposome particles with controlled release of citrus unshiu peel extracts. Materials Chemistry and Physics, 208, 183-188. http://dx.doi.org/10.1016/j. matchemphys.2018.01.027.

Lin, Y., Knol, D., Menéndez-Carreño, M., Baris, R., Janssen, H. G., \& Trautwein, E. A. (2018). Oxidation of sitosterol and campesterol in foods upon cooking with liquid margarines without and with added 
plant sterol esters. Food Chemistry, 241, 387-396. http://dx.doi. org/10.1016/j.foodchem.2017.08.118. PMid:28958544.

Liu, S., Hu, H., \& Li, C. (2016). Antioxidant activities of novel galloyl phytosterols evaluated by human erythrocytes with the aid of confocal microscopy imaging. Journal of Functional Foods, 22, 224-231. http:// dx.doi.org/10.1016/j.jff.2016.01.026.

Luo, C., Cheng, Y., Yi, Y., Xia, B., Zhou, H., \& Cao, X. (2016). Optimization of Preparation Process for Blend Microcapsules of Phytosterol Esters and Puerarin. Shipin Kexue, 37, 26-33.

Malcolmson, R. J., Higinbotham, J., Beswick, P. H., Privata, P. O., \& Saunier, L. (1997). DSC of DMPC liposomes containing low concentrations of cholesteryl esters or cholesterol. Journal of Membrane Science, 123(2), 243-253. http://dx.doi.org/10.1016/S0376-7388(96)00219-0.

Marín, D., Alemán, A., Montero, P., \& Gómez-Guillén, M. C. (2018). Encapsulation of food waste compounds in soy phosphatidylcholine liposomes: Effect of freeze-drying, storage stability and functional aptitude - ScienceDirect. Journal of Food Engineering, 223, 132-143. http://dx.doi.org/10.1016/j.jfoodeng.2017.12.009.

Mohan, A., McClements, D. J., \& Udenigwe, C. C. (2016). Encapsulation of bioactive whey peptides in soy lecithin-derived nanoliposomes: Influence of peptide molecular weight. Food Chemistry, 213, 143-148. http://dx.doi.org/10.1016/j.foodchem.2016.06.075. PMid:27451165.

Monpara, J., Kanthou, C., Tozer, G. M., \& Vavia, P. R. (2018). Rational design of cholesterol derivative for improved stability of paclitaxel cationic liposomes. Pharmaceutical Research, 35(4), 90. http://dx.doi. org/10.1007/s11095-018-2367-8. PMid:29520495.

Niaz, T., Shabbir, S., Noor, T., Rahman, A., Bokhari, H., \& Imran, M. (2018). Potential of polymer stabilized nano-liposomes to enhance antimicrobial activity of nisin $\mathrm{Z}$ against foodborne pathogens. Lebensmittel-Wissenschaft + Technologie, 96, 98-110. http://dx.doi. org/10.1016/j.lwt.2018.05.029.

Nkanga, C. I., \& Krause, R. W. M. (2018). Conjugation of isoniazid to a zinc phthalocyanine via hydrazone linkage for $\mathrm{pH}$-dependent liposomal controlled release. Applied Nanoscience, 8(6), 1313-1323. http://dx.doi.org/10.1007/s13204-018-0776-y.

Okafor, N. I., Nkanga, C. I., \& Walker, R. B. (2019). Encapsulation and physicochemical evaluation of efavirenz in liposomes. Journal of Pharmaceutical Investigation, 50(1), 201-208.

Paliwal, S., Tilak, A., Sharma, J., Dave, V., Sharma, S., Verma, K., Tak, K., Reddy, K. R., \& Sadhu, V. (2019). Flurbiprofen-loaded ethanolic liposome particles for biomedical applications. Journal of Microbiological Methods, 161, 18-27. http://dx.doi.org/10.1016/j. mimet.2019.04.001. PMid:30951793.

Panpipat, W., Dong, M., Xu, X., \& Guo, Z. (2013). Thermal properties and nanodispersion behavior of synthesized $\beta$-sitosteryl acyl esters: A structure-activity relationship study. Journal of Colloid and Interface Science, 407, 177-186. http://dx.doi.org/10.1016/j.jcis.2013.06.030. PMid:23871599.

Pega, J., Pérez, C. D., Rizzo, S., Rossetti, L., Díaz, G., Ruzal, S. M., Nanni, M., \& Descalzo, A. M. (2017). The incorporation of alpha-tocopherol and functional doses of phytosterol esters during cheesemaking does not affect DNA or mRNA dynamics of Streptococcus therrnophilus and Lactococcus lactis throughout and after the end of ripening. Lebensmittel-Wissenschaft + Technologie, 84, 838-841. http://dx.doi. org/10.1016/j.lwt.2017.06.057.
Piazzini, V., Landucci, E., Graverini, G., Pellegrini-Giampietro, D., Bilia, A., \& Bergonzi, M. (2018). Stealth and cationic nanoliposomes as drug delivery systems to increase andrographolide BBB permeability. Pharmaceutics, 10(3), 128-147. http://dx.doi.org/10.3390/ pharmaceutics10030128. PMid:30104484.

Pinilla, C. M. B., Thys, R. C. S., \& Brandelli, A. (2019). Antifungal properties of phosphatidylcholine-oleic acid liposomes encapsulating garlic against environmental fungal in wheat bread. International Journal of Food Microbiology, 293, 72-78. http://dx.doi.org/10.1016/j. ijfoodmicro.2019.01.006. PMid:30660071.

Rui, X., Wenfang, L., Jing, C., Meng, C., Chengcheng, D., Jiqu, X., \& Shuang, R. (2017). Neuroprotective effects of phytosterol esters against high cholesterol-induced cognitive deficits in aged rat. Food \& Function, 8(3), 1323-1332. http://dx.doi.org/10.1039/C6FO01656A. PMid:28256666.

Salmon, A., \& Hamilton, J. A. (1995). Magic-Angle Spinning and Solution 13C Nuclear Magnetic Resonance Studies of Medium- and LongChain Cholesteryl Esters in Model Bilayers. Biochemistry, 34(49), 16065-16073. http://dx.doi.org/10.1021/bi00049a021. PMid:8519763.

Savaghebi, D., Barzegar, M., \& Mozafari, M. R. (2019). Manufacturing of nanoliposomal extract from Sargassum boveanum algae and investigating its release behavior and antioxidant activity. Food Science \& Nutrition, 8(1), 299-310. http://dx.doi.org/10.1002/ fsn3.1306. PMid:31993156.

Schmid, M., Wölk, C., Giselbrecht, J., Chan, K. L. A., \& Harvey, R. D. (2018). A combined FTIR and DSC study on the bilayer-stabilising effect of electrostatic interactions in ion paired lipids. Colloids and Surfaces. B, Biointerfaces, 169, 298-304. http://dx.doi.org/10.1016/j. colsurfb.2018.05.031. PMid:29793092.

Scholz, B., Menzel, N., Lander, V., \& Engel, K. H. (2016). Heating Two Types of Enriched Margarine: Complementary Analysis of Phytosteryl/ Phytostanyl Fatty Acid Esters and Phytosterol/Phytostanol Oxidation Products. Journal of Agricultural and Food Chemistry, 64(13), 26992708. http://dx.doi.org/10.1021/acs.jafc.6b00617. PMid:26996218.

Tai, K., Liu, F., He, X., Ma, P., Mao, L., Gao, Y., \& Yuan, F. (2018). The effect of sterol derivatives on properties of soybean and egg yolk lecithin liposomes: stability, structure and membrane characteristics. Food research international (Ottawa, Ont.), 109, 24-34. http://dx.doi. org/10.1016/j.foodres.2018.04.014. PMid:29803447.

Tai, K., Rappolt, M., He, X., Wei, Y., Zhu, S., Zhang, J., Mao, L., Gao, Y., \& Yuan, F. (2019). Effect of $\beta$-sitosterol on the curcumin-loaded liposomes: Vesicle characteristics, physicochemical stability, in vitro release and bioavailability. Food Chemistry, 293, 92-102. http://dx.doi. org/10.1016/j.foodchem.2019.04.077. PMid:31151654.

Wang, F. C., Acevedo, N., \& Marangoni, A. G. (2017). Encapsulation of phytosterols and phytosterol esters in liposomes made with soy phospholipids by high pressure homogenization. Food \& Function, 10(11), 1039. http://dx.doi.org/10.1039/C7FO00905D.

Wei, X., Patil, Y., Ohana, P., Amitay, Y., Shmeeda, H., Gabizon, A., \& Barenholz, Y. (2017). Characterization of pegylated liposomal mitomycin C lipid-based prodrug (Promitil) by high sensitivity differential scanning calorimetry and cryogenic transmission electron microscopy. Molecular Pharmaceutics, 14(12), 4339-4345. http:// dx.doi.org/10.1021/acs.molpharmaceut.6b00865. PMid:28045540. 